\title{
A Universal Method to Create Surface Patterns with Extreme Wettability on
}

\section{Metal Substrates}

\author{
Jing Sun ${ }^{\mathrm{a}}$, Chuanzhen Chen ${ }^{\mathrm{a}}$, Jinlong Song ${ }^{\mathrm{a}, \mathrm{b}, *}$, Junkai Liu ${ }^{\mathrm{a}}$, Xiaolong Yang ${ }^{\mathrm{a}}$, Jiyu Liu ${ }^{\mathrm{a}}$, Xin Liu, ${ }^{\mathrm{a}, \mathrm{b}}$, Yao Lu ${ }^{\mathrm{c}, *}$ \\ ${ }^{a}$ Key Laboratory for Precision and Non-traditional Machining Technology of the Ministry of Education, Dalian University \\ of Technology, Dalian 116024, P. R. China. \\ ${ }^{\mathrm{b}}$ Collaborative Innovation Center of Major Machine Manufacturing in Liaoning, Dalian University of Technology, Dalian \\ 116024, China. \\ ${ }^{\mathrm{c}}$ Department of Mechanical Engineering, University College London, Torrington Place, London WC1E 7JE, UK
}

\section{Abstract}

Extreme wettability surfaces have attracted more and more attention due to their practical applications, however, few reports have shown a universal method to create surface patterns with extreme wettability on a variety of metals. In this paper, a mask-assisted dual-chemical-processing approach without special modification is used to prepare the extreme wettability patterns on various metal substrates. Fabrication of superhydrophilic-superhydrophobic patterns on five kinds of metal substrates of Al, Ti, steel, $\mathrm{Zn}$ and $\mathrm{Mg}$ alloy proved the versatility of this method. The extreme wettability patterns prepared by this method were applied to fog harvest and we found the big differences in the collection efficiency of various metal surface patterns.

Keywords: Extreme wettability; Universal method; Various metal; Fog harvest

\section{Introduction}

Extreme wettability is a special phenomenon in nature due to the microstructures and surface free energy. Wettability refers to the spreading ability of the liquid on a solid surface and is quantified by the contact angle. A solid surface with a water contact angle (CA) higher than $150^{\circ}[1-4]$ is a superhydrophobic surface; when the CA of a surface is less than $5^{\circ}$, it is called a superhydrophilic surface. These surfaces have been intensely investigated in different domains thanks to their wide applications in various technical areas such as drag reduction [5], self-cleaning [6-7], anti-icing [8-10], anti-corrosion [11-12], oil/water separation [13-14], etc. Extreme wettability patterns refer to surfaces containing both superhydrophobic and superhydrophilic regions, and these properties enable the control of fluids that are water-based, which have been widely applied in modern science and technology, such as cell growth [15], manipulation of egg quality [16], determination of biomolecules [17] in biotechnology, microfluidic localization in microfluidics, control and mixing of liquid geometry [18-19], lithography [20], etc.

To date, various methods have been developed for the fabrication of extreme wettability patterned surfaces, such as printing technology [21], chemical vapor deposition [22], ultraviolet irradiation [23-24], plasma modification [25-27], etc. Lai et al. [28] fabricated high-accuracy superhydrophobic patterns on a superhydrophobic $\mathrm{TiO}_{2}$ nanotube array (TNA) surface by photocatalytic lithography with a two-step process and can easily control the dimension and morphology of the patterns. Liu et al. altered a fluoroalkylsilane modified superhydrophobic surface to achieve superhydrophilicity using atmospheric pressure plasma treatment, and different superhydrophilic patterns can be obtained with the combination of mask technique. Kinoshita et al. [29] used a laser plasma-type hyperthermal atom beam facility to achieve superhydrophilic-superhydrophobic micro-nanostrucutures on carbon nanotube (CNT) films. Yang et al. [30] fabricated the superhydrophilic-superhydrophobic patterned surface on metal superhydrophobic substrates using a two-step electrochemical-etching method. Combining the masked electrochemical etching and boiling-water immersion methods, they prepared long-term superhydrophilic dimples on the superhydrophobic Al substrate. However, most of methods to creat superhydrophilic region on a superhydrophobic surface require either complex technology or high cost, which has limited applications of extreme wettability patterns. From the perspective of complexity, many fabrication methods are not applied widely in the practical production because of their complicated manipulating process and unstable materials, which are

Corresponding author. Email address: songjinlong@dlut.edu.cn (J, L. Song), yao.lu@ucl.ac.uk (Y. Lu) 
susceptible to contamination and infelicity in the large-scale production. From the perspective of serviceability, most methods can't be utilized in various kinds of metal substrates. Additionally, from the perspective of cost, many methods should be conducted in expensive equipment or special apparatus. Their production processes are relatively complex and 1 products prepared are not timely. All of these factors hamper the development of materials regarding extreme wettability

2 patterns in a wide scale.

Water-collecting methods for superhydrophobic surfaces with hydrophilic patterns have been well understood, which is inspired by the efficient fog-harvesting behavior of Stenocara beetles in the Namib Desert [31]. A superhydrophilic-superhydrophobic patterned surface that was similar to the back of a desert beetle can be applied for high-efficient fog harvest in the drought environment [32-34]. Zhang's group used ink-jet printing technology to make superhydrophilic patterns on the superhydrophobic surface of the desert beetle, showing powerful catchment capability. Yang et al. [30] fabricated different superhydrophilic-superhydrophobic patterns on the Al surface by using the two-step electrochemical etching method and studied the effect of different wettability patterns on the fog collection efficiency. However, the effect of the patterned surfaces of different metallic materials on the efficiency of the fog harvesting process is rarely reported.

Developing a low-cost, simple, fast, and generally applicable technique to fabricate superhydrophilic-superhydrophobic patterns on various metal surfaces is a challenging research topic. Here, a mask-assisted dual-chemical-processing approach is proposed to prepare extreme wettability patterns on various metal substrates; this method does not require expensive equipment or complex operations. Superhydrophobicity and superhydrophilicity can be achieved after dual chemical processing. Based on the principle of liquid polarity incompatibility, underwater superoleophobicity and superoleophilicity of extreme wettability patterns were successfully achieved. The obtained patterns could maintain their extreme wettability or at least 30 days.

Water scarcity is a severe problem in semi-arid desert regions, land-scarce countries and in countries with high levels of economic activity. In these areas, it is considered to be an important method of providing water by collecting atmospheric water such as fog. The patterned superhydrophobic surfaces integrated two properties into one surface, leading to a better water collection performance than their uniformly superhydrophobic and superhydrophilic counterparts [33]. In particular, surfaces with star-shaped patterns can collect more water. Using the two-step chemical processing method, the same superhydrophilic-superhydrophobic pattern designed and fabricated on different metal surfaces for fog harvesting test were carried out.

\section{Experimental Section}

\subsection{Materials}

Aluminum (Al) plates (40 mm $\times 40 \mathrm{~mm} \times 2 \mathrm{~mm}$; purity: 99.9\%) were purchased from the Dalian Aluminum Material Manufacturer (China). $\mathrm{CuCl}_{2}$ and acetone were purchased from Tianjin Camel Chemical Reagent manufacturer (China). The fluoroalkylsilane [FAS, $\mathrm{C}_{8} \mathrm{~F}_{13} \mathrm{H}_{4} \mathrm{Si}\left(\mathrm{OCH}_{2} \mathrm{CH}_{3}\right)_{3}$ ] was purchased from Tianjin GuangFu Fine Chemical Research Institute. 304 stainless steel $(40 \mathrm{~mm} \times 40 \mathrm{~mm} \times 2 \mathrm{~mm})$, ferric chloride, hydrochloric acid (37wt\%), phosphoric acid (85wt\%), and hydrogen peroxide (30wt\%) were all purchased from Bailingwei Technology Co., Ltd. AZ61 Mg alloy was purchased from Dongguan Jiahao Die Materials Co., China. Titanium (Ti) plates $(20 \mathrm{~mm} \times 30 \mathrm{~mm} \times 2 \mathrm{~mm})$ were purchased from Dalian Shenghui Titanium Industry Co., Ltd. Zinc (Zn) plate $(40 \mathrm{~mm} \times 40 \mathrm{~mm} \times 2 \mathrm{~mm})$, sulfuric acid (98wt\%), copper sulfate pentahydrate, anhydrous ethanol (AR) and the rest of the chemicals used in the experiment were all purchased from Sinopharm Chemical Reagent Co., Ltd. All chemicals were of analytical grade and were used as received.

\subsection{Universal method for fabricating superhydrophilic-superhydrophobic patterns}

A two-step chemical processing method was employed to fabricate the extreme wettability patterns on various metal substrates. Step I: Fabrication of superhydrophobic region [Figure 1]. Firstly, a metal plate was polished by sandpapers to remove the oxide layer, and then ultrasonically cleaned in alcohol and deionized water solvents in sequence. After drying in air, the designed pattern was scribed on the mask and then the mask was bonded on the metal plate. Secondly, the metal substrate was put into the corresponding solution for chemical immersion to obtain the micro/nanostructures, followed by the modification of $0.1 \mathrm{~mol} \mathrm{~L}^{-1}$ ethanol solution of fuoroalkylsilane for 40 minutes to reduce surface energy. Then, the metal was heated at $120{ }^{\circ} \mathrm{C}$ for $20 \mathrm{~min}$ to obtain the superhydrophobic region. Finally, the chemically processing region became superhydrophobic, while the masked region retained their original wettability. Here, corresponding solutions refer to: $\mathrm{Al}$ 
was etched by $1 \mathrm{~mol} \mathrm{~L}^{-1}$ aqueous $\mathrm{CuCl}_{2}$ solution. 304 stainless steel was etched by $21 \mathrm{wt} \% \mathrm{FeCl}_{3}$ adding $2 \mathrm{ml} \mathrm{HCl}, 2 \mathrm{ml}$ $\mathrm{H}_{3} \mathrm{PO}_{4}$, and $2 \mathrm{ml} \mathrm{H}_{2} \mathrm{O}_{2}$. Ti was etched by $\mathrm{H}_{2} \mathrm{SO}_{4}$ concentration of $72 \%$. $\mathrm{Zn}$ was deposited by the mixed solution of $0.1 \mathrm{~mol}$ $\mathrm{L}^{-1} \mathrm{H}_{2} \mathrm{SO}_{4}$ and $0.2 \mathrm{~mol} \mathrm{~L}^{-1} \mathrm{CuSO}_{4}$. $\mathrm{Mg}$ alloy was immersed by $0.2 \mathrm{~mol} \mathrm{~L}^{-1}$ aqueous $\mathrm{CuSO}_{4}$ solution. Step II: Fabrication of 1 superhydrophilic region [Figure 1]. Firstly, the mask was removed from the metal substrate. Then, chemical solution was dropped onto the hydrophilic region that was previously covered by the mask. During the reaction process, the chemical solution only spread on the hydrophilic region and the previously masked region was fabricated to become superhydrophilic. After the above-mentioned two steps, patterns with superhydrophobic and superhydrophilic areas had been prepared.
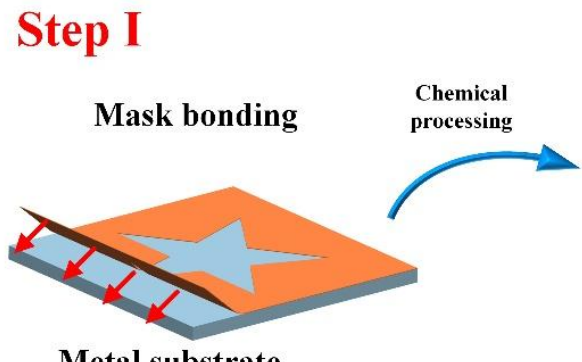

Metal substrate

Superhydrophilic region
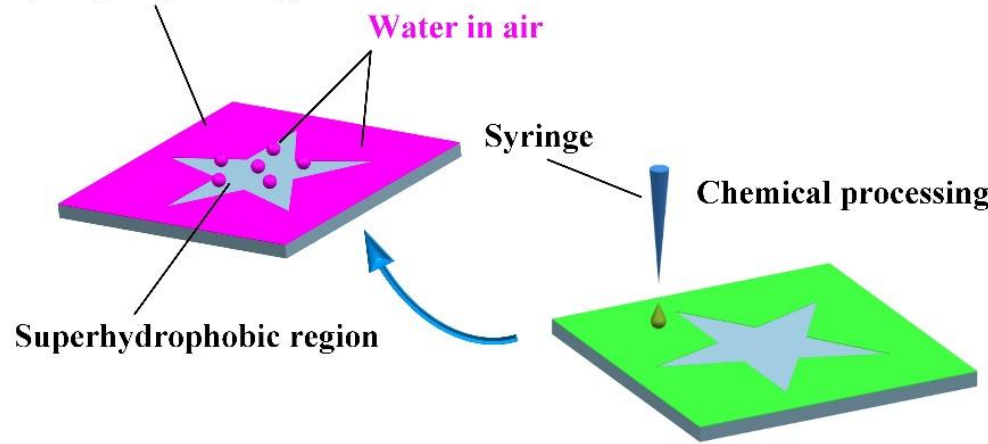

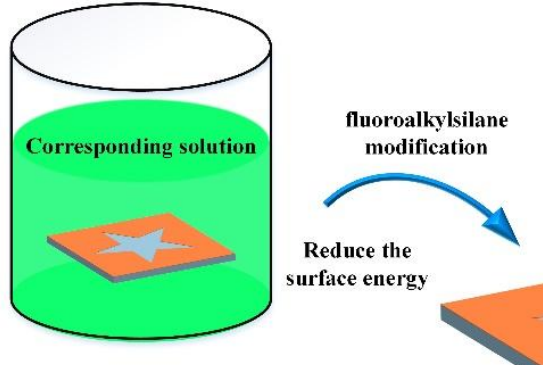

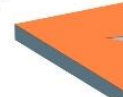

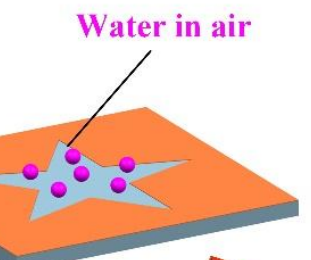

Figure 1. Fabrication process of extreme wettability patterns. Step I: Fabrication of superhydrophobic region by mask based chemical processing and fluoroalkylsilane modification. Step II: Fabrication of superhydrophilic region by chemical processing with dropping liquids.

\subsection{Characterization}

Scanning electron microscopy (SEM, EVOLS15, the United Kingdom Zeiss company) was used to characterize the surface morphology. Electrochemical workstation (Princeton Applied Research, VersaSTAT, USA) was used to test potentiodynamic polarization curves. The polarization curves were investigated in $3.5 \mathrm{wt} \%$ aqueous $\mathrm{NaNO}_{3}$ solution with a sweep rate of $2 \mathrm{mV} / \mathrm{s}$. The chemical composition of the samples was examined by X-ray diffractometer system (XRD-6000, Japan), and a Fourier transform infrared spectrophotometer (FTIR, EQUINOX55 155 Germany). The X-ray source was a CuKa radiation $(\mathrm{k}=0.15418 \mathrm{~nm})$, which was operated at a scanning rate of $2 \mathrm{~h}=0.026 \mathrm{deg} / \mathrm{min}$ and at $40 \mathrm{kV}$ and $40 \mathrm{~mA}$ within the 20-100 range. Contact angles (CAs) and rolling angles (RAs) were investigated by an optical contact angle meter (Kruss, DSA100, Germany) at room temperature. CA and RA values are the averages of five measurements at five different locations.

\subsection{Fog harvest measurements}

The prepared sample was mounted on a sample holder in a glass box with a sliding roof (length $\times$ width $\times$ height: $500 \times$ $300 \times 500 \mathrm{~mm})$. The sample was vertically positioned and a culture dish was placed under the sample. The surface of sample was facing the nozzle of the mist generator, and the distance between the sample and the nozzle was 35 mm. Simulated fog was generated by a household humidifier (humidifying capacity: $300 \mathrm{ml} \mathrm{h}^{-1}$, power: $25 \mathrm{~W}$ ). Water that condensed on the substrate was drained by gravity into the dish below. Water droplets harvested within 30 minutes were weighed by a precision balance (resolution: $0.1 \mathrm{mg}$ ).

\section{Results and discussion}

\subsection{Fabrication of extreme wetting patterns on an Al plate}


A two-step chemical method was employed to fabricate extreme wettability patterns on Al plates. Step I: Fabrication of superhydrophobic region by masked chemical etching and fuoroalkylsilane modification [Figure 1]. Firstly, the designed pattern was engraved on the mask [Figure 2a], then a mask with a designed shape was bonded on the processed $\mathrm{Al}$ plate

(a)

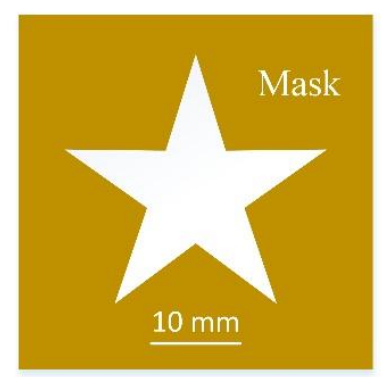

(d)

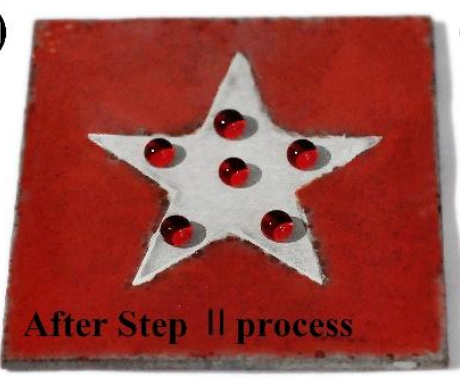

Water in air (b)

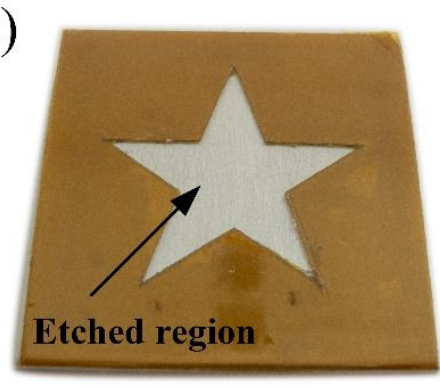

(e)

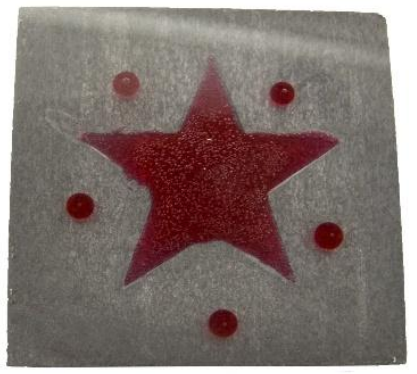

Dichloromethane in water (c)

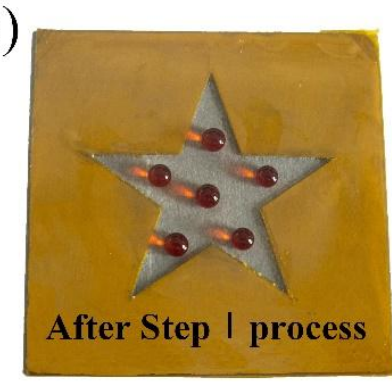

(f)

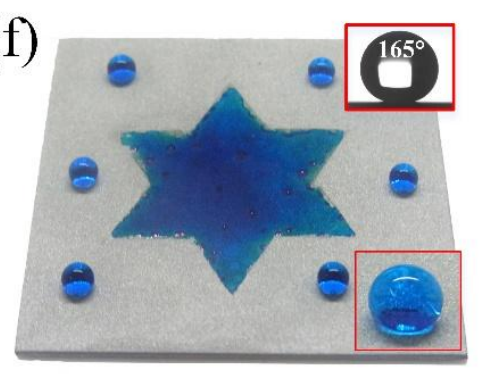

Other etched patterns

Figure 2. (a) Masking template for extreme wettability pattern with single-superhydrophilic region. (b) Process of mask based chemical etching. (c) Water droplets (dyed red) were positioned on the superhydrophobic area after chemical etching. (d) Water (dyed red) on extreme wettability pattern in air. (e) Dichloromethane (dyed red) on extreme wettability pattern with water-film protection. (f) Water (dyed blue) on other wettability pattern in air.

Figure 3 shows the SEM images of the patterned Al surface with extreme wettability. Compared with untreated $\mathrm{Al}$ surfaces (see Supplementary Material Figure S1), the superhydrophobic Al surfaces were completely etched and covered by irregular pits and protrusions [Figure 3a-b]. Many rectangular-shaped plateaus with the size of 1-5 $\mu \mathrm{m}$ were evenly distributed on the pits and protrusions. The two etched regions had obvious boundary, separating the superhydrophilic region from the superhydrophobic region [Figure 3c-d]. The microstructure of superhydrophilic Al surfaces after etching with mask covering was almost unchanged [Figure 3e-f], indicating that low surface energy modification and mask covering did not cause structure change of Al surfaces. 

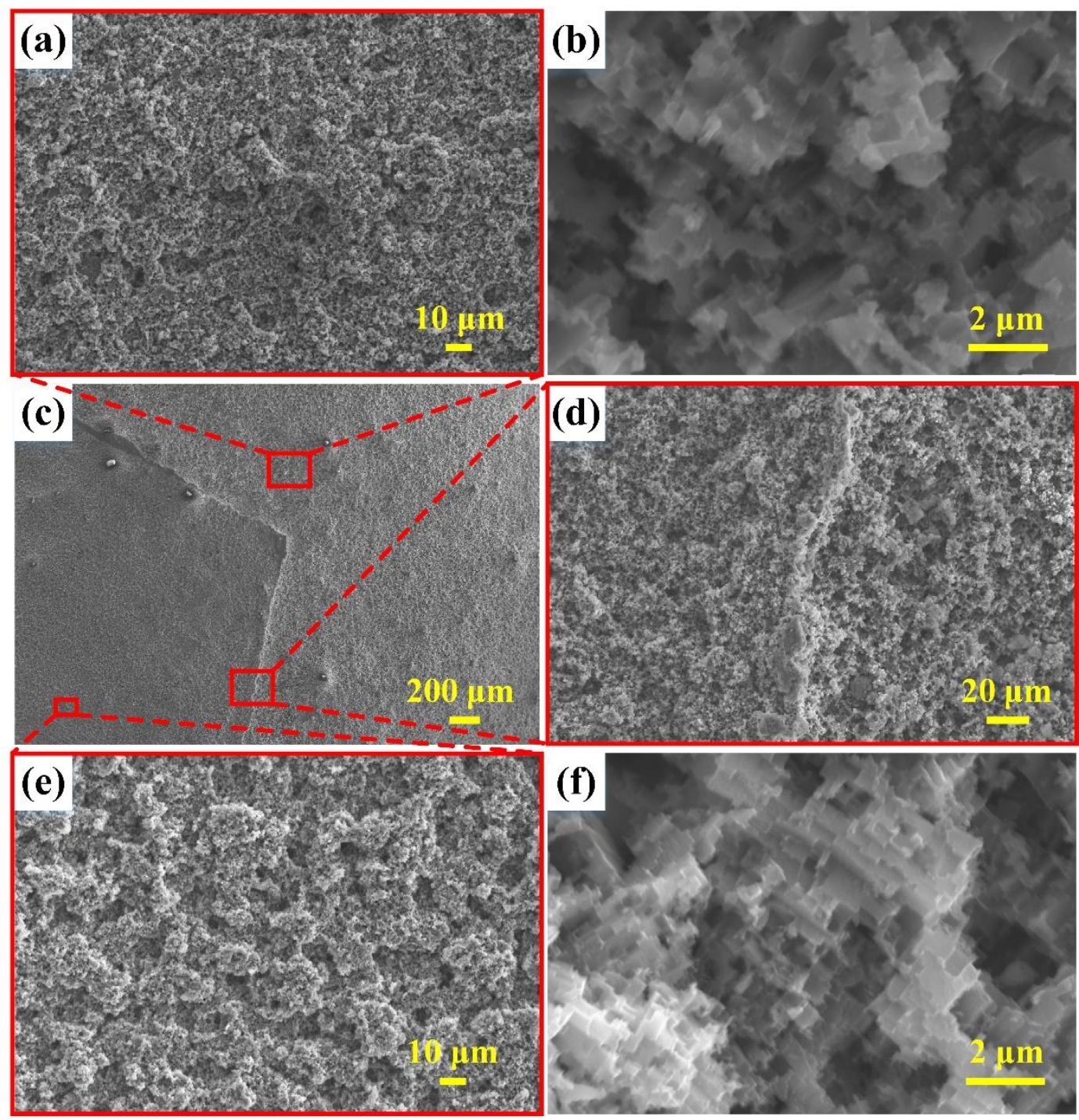

Figure 3. SEM images of etched Al surfaces: (a)-(b) superhydrophobic region, (c)-(d) boundary of dual etching regions, and (e)-(f) superhydrophilic region.

Figure 4a displays the potentiodynamic polarization curves of superhydrophobic, superhydrophilic and ordinary surfaces. Ordinary surfaces were polished before testing to remove the oxide layer. Open-circuit voltages of three surfaces are all less than zero, and the open circuit voltage of superhydrophobic surface (the inflection point of the curve in Figure 4) is greater than that of superhydrophilic surface, while that of superhydrophilic surface is greater than the ordinary surface. The surface will not be corroded when the potential is less than the open-circuit voltage [35-36], whereas the surface will be broken by aqueous $\mathrm{CuCl}_{2}$ solution if the potential exceeds the inflection point. In addition, the corrosion current density of superhydrophobic surface is much lower than those of the ordinary and superhydrophilic surfaces. Such a low current density indicates excellent corrosion resistance on the superhydrophobic $\mathrm{Al}$ surface. When etching solution was dropped onto the ordinary area on the surface during Step II, the aqueous $\mathrm{CuCl}_{2}$ solution could not wet or etch the superhydrophobic region due to its superhydrophobicity.

Figure $4 \mathrm{~b}$ shows the Fourier transform infrared (FTIR) spectra of the etched Al surfaces before and after FAS modification, respectively. After FAS modification, seven absorption bands at around 1365, 1317, 1240, 1208, 1143, 1117, and $1067 \mathrm{~cm}^{-1}$ appeared. Among these peaks, the absorption bands at $\sim 1365,1317,1240,1208,1143$, and $1117 \mathrm{~cm}^{-1}$ are assigned to the C-F stretching vibration of the of the $-\mathrm{CF}_{2}$ - and $-\mathrm{CF}_{3}$ groups of the FAS molecules, whereas the peak at 1067 $\mathrm{cm}^{-1}$ is due to Si-O-Si bonds [37-38]. Therefore, the FTIR spectra show that these etched Al surfaces were passivated with FAS molecules to produce low energy surfaces. 

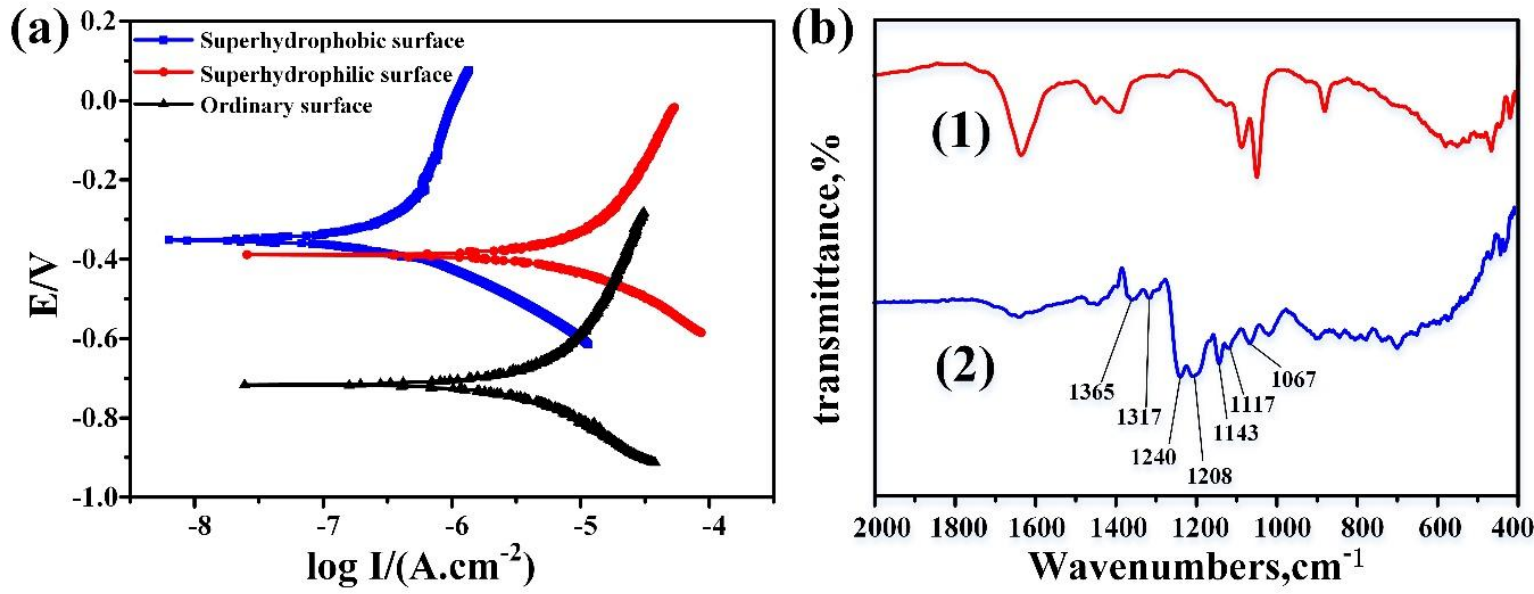

Figure 4. (a) Potentiodynamic polarization curves of superhydrophobic surface, superhydrophilic surface and ordinary surface. (b) FTIR spectra of the etching Al surfaces (1) before and (2) after FAS modification.

Figure 5a shows the XRD patterns of the polished $\mathrm{Al}$ surfaces after ultrasonic cleaning and the etched $\mathrm{Al}$ surfaces after immersion in aqueous $\mathrm{CuCl}_{2}$ solution for $20 \mathrm{~s}$. It can be seen from the figure that only $\mathrm{Al}$ diffraction peaks existed on the surfaces of the ordinary $\mathrm{Al}$ and the etched $\mathrm{Al}$, indicating that no new product was formed on the surface of the chemical etched Al. Four diffraction peaks of the etched $\mathrm{Al}$ surfaces at $2 \theta=38.16^{\circ}, 44.38^{\circ}, 64.84^{\circ}$, and $78.06^{\circ}$ are assigned to the $\mathrm{Al}(111), \mathrm{Al}(200), \mathrm{Al}(220)$, and $\mathrm{Al}(311)$ planes of $\mathrm{Al}$ (JCPDS Card No. 04-0787). The XRD patterns of four other metals before and after chemical processing are shown in Supplementary Material Figure S2. Figure 5b shows the variation in water contact angles of the $\mathrm{Al}$ surface at different chemical etching times in the two-step process. In step I, with the increase of etching time, the average contact angle of the etched surface increased gradually and reached $160^{\circ}$ after 5 seconds (water contact angles were measured after fuoroalkylsilane modification). After etching for 10 seconds, the contact angle kept stable. In step II, the superhydrophobic region modified by Step I still showed superhydrophobicity, although the contact angles slightly decreased, they remained stable during the chemical etching process, indicating that the secondary etching had little effect on the superhydrophobic region. For the region that was previously covered by the mask, the superhydrophilic surface with a water contact angle of $\sim 3^{\circ}$ could be obtained when the etching time was 10 seconds, and then the contact angle kept stable with the increase of the etching time.
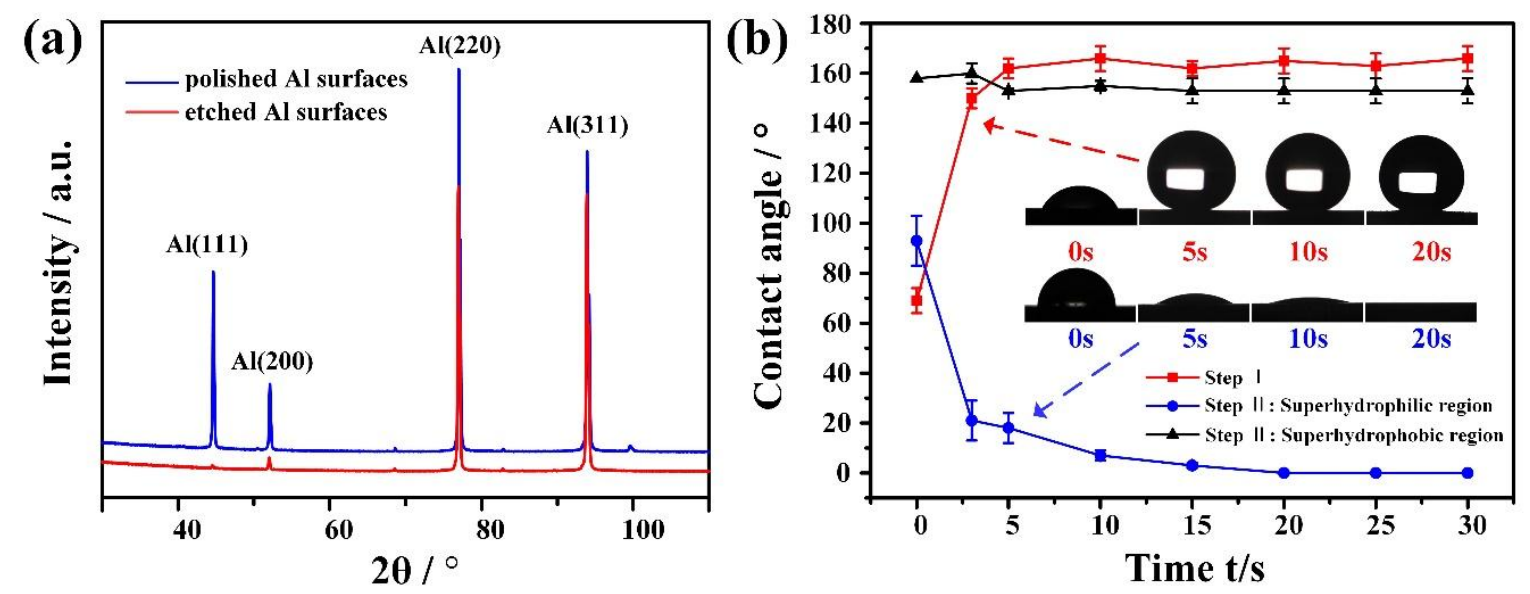

Figure 5. (a) X-ray diffraction (XRD) patterns of polished Al surface and the etched Al surface. (b)Variation in the water contact angles with the processing time.

\subsection{Fabrication of extreme wetting patterns on a Ti plate}

This two-step chemical processing method can also be applied to other metal substrates. Extreme wettability patterns were prepared on the Ti plate. The Ti plate was etched in a solution containing $72 \% \mathrm{H}_{2} \mathrm{SO}_{4}$ for 30 minutes at $120{ }^{\circ} \mathrm{C}$, and micro/nanostructure was obtained. After fluoroalkylsilane modification, the superhydrophobic region of the Ti surface was obtained [Figure 6a]. The water contact angle in this region reached $165^{\circ}$ and the rolling angle was $4^{\circ}$. In Step II, the $\mathrm{H}_{2} \mathrm{SO}_{4}$ solution was dropped onto the hydrophilic region that was previously covered by the mask at $120{ }^{\circ} \mathrm{C}$ to obtain a superhydrophilic area on the Ti surface. After the above-mentioned two steps, extreme wettability patterns containing both 
superhydrophobic and superhydrophilic regions were prepared [Figure 6b]. Figure 6c shows an underwater superoleophilic and superoleophobic pattern prepared on a plate. Besides, through this dual etching method, various extreme wetting patterns can be also fabricated on Ti plates (see Supplementary Material Figure S1).

1 Figure 6d-f shows the SEM images of the extreme wettability patterns on the Ti surface. The honeycomb-like structure

2

3

(the average diameter was $\sim 36 \mu \mathrm{m}$ ) as shown in Figure $6 \mathrm{~d}$ was formed on etched Ti substrate, in the SEM image of higher magnification, wave-like morphology with diameters of $0.5-2 \mu \mathrm{m}$ could be observed. The reason is that the chemical etching took place at different etching rate in different crystallographic directions in the Ti crystals [39-40]. After the chemical etching in Step II, a clear boundary was formed between the superhydrophobic and superhydrophilic regions, as shown in Figure 6e. Figure $6 \mathrm{f}$ shows the SEM images of the superhydrophilic region, it demonstrates similar micro morphologies as those in the superhydrophobic region.
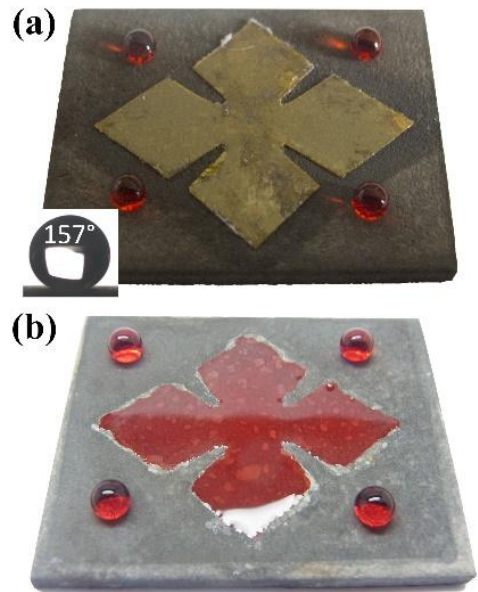

(c)

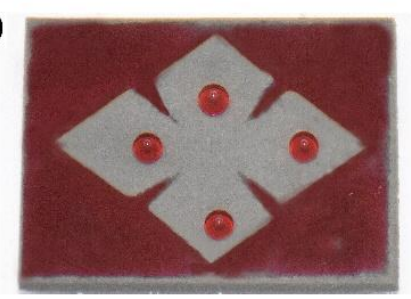

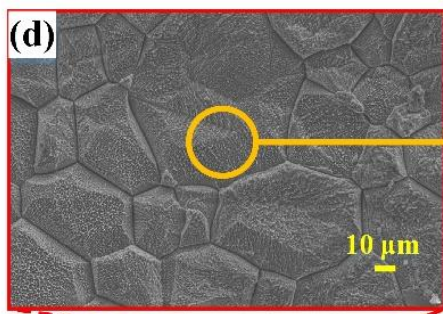
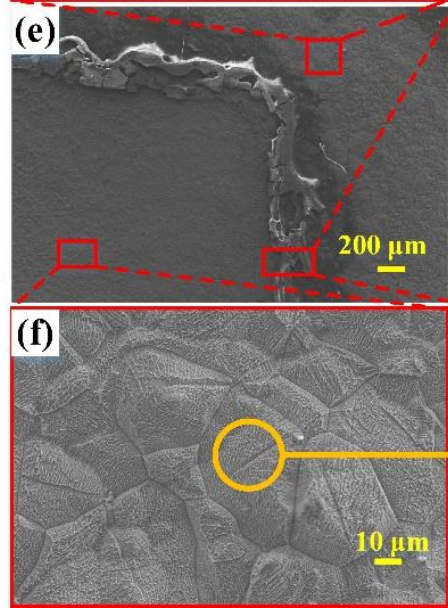

Figure 6. Fabrication of extreme wettability patterns on Ti substrate. (a) Water droplets (dyed red) were positioned on the superhydrophobic area after chemical etching in Step I. (b) Water (dyed red) on extreme wettability patterns in air after processing of Step II. (c) Dichloromethane (dyed red) on extreme wettability patterns of Ti surface that was immersed in water. SEM images of etched Ti surfaces at different magnifications: (d) superhydrophobic region, (e) the boundary of the two etched regions, and (f) superhydrophilic region obtained by secondary etching in Step II.

\subsection{Fabrication of extreme wetting patterns on a steel plate}

Figure 7 shows extreme wettability patterns on a steel plate that were processed using the two-step chemical etching method. $8.0 \mathrm{~g}$ of $\mathrm{FeCl}_{3}$ was dissolved in $30 \mathrm{ml}$ deionized water and stirred until completely dissolved. Then, $2 \mathrm{ml}$ of $\mathrm{HCl}, 2$ $\mathrm{ml}$ of $\mathrm{H}_{3} \mathrm{PO}_{4}$ and $2 \mathrm{ml}$ of $\mathrm{H}_{2} \mathrm{O}_{2}$ were added to form the etching solution. The steel substrate was immersed in the etching solution for over $20 \mathrm{~min}$. After fluorosilane modification, superhydrophobic surface [Figure 7a] was obtained. The contact angle of the water droplets in this region reached $162^{\circ}$ and the rolling angle was $7^{\circ}$. In Step II, the etching solution was dropped on the region that was previously covered by the mask to obtain a superhydrophilic surface. After these two steps, superhydrophilic-superhydrophobic patterns had been successfully prepared [Figure 7b]. Similarly, underwater superoleophilic and superoleophobic patterns could also be prepared [Figure 7c]. Through this dual etching method, we can fabricate extreme wettability patterns of various shapes on steel substrate (see Supplementary Material Figure S3).

A number of irregular pits and protrusions were formed uniformly on the surface of the etched stainless steel [Figure 7d]. It can be seen from the image with higher magnification that the concavities and convexities were connected to each other to form "honeycomb" structures on the surface. There were many small papillate structures among these protruded structures which were embedded in the pits of the surface and these structures were very similar to the fine structure on the lotus leaf surface. As shown in Figure 7e, the boundary between the superhydrophobic and superhydrophilic regions was clearly demarcated. The structure of superhydrophilic region after second etching was similar to that of the superhydrophobic region, which was still the honeycomb-like structure [Figure 7f]. 

Figure S3). (a)

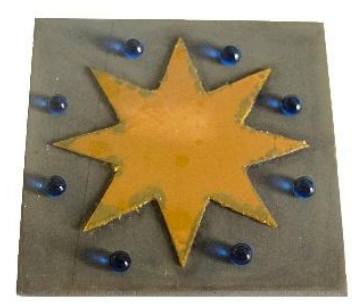

(b)

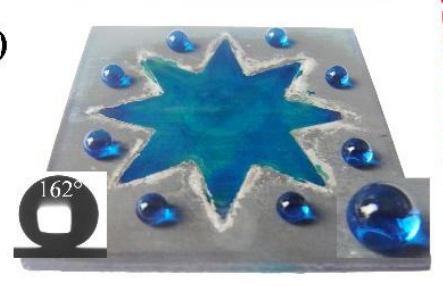

(c)

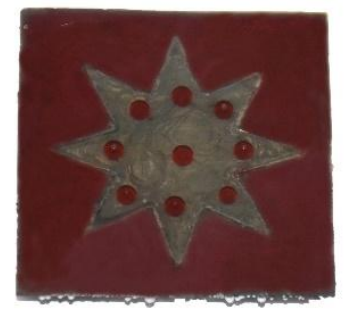

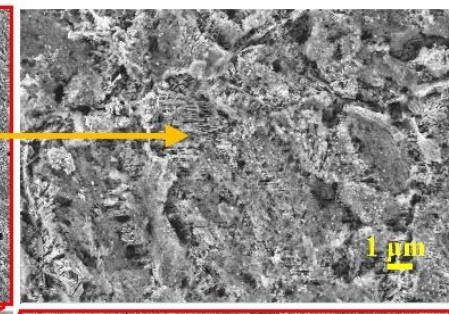
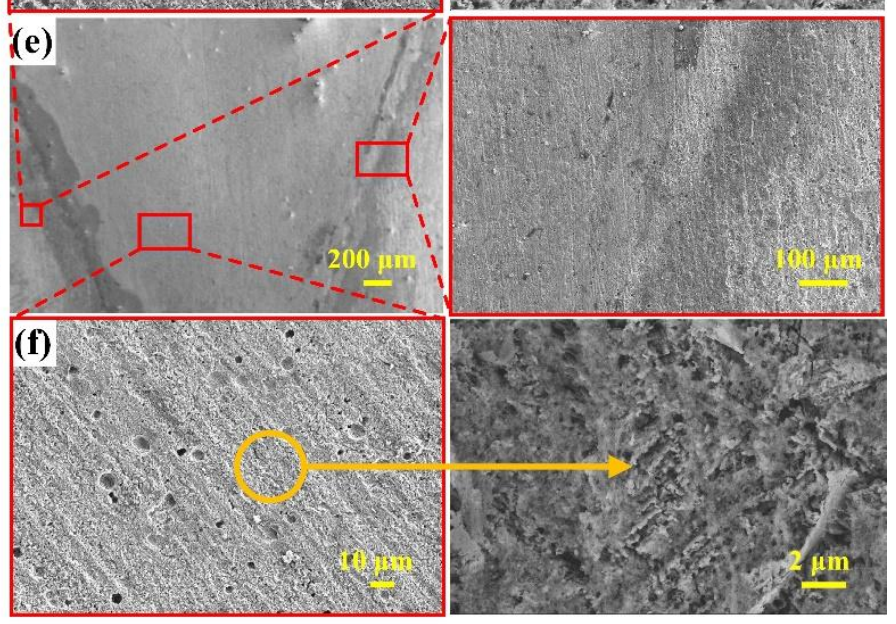

Figure 7. Fabrication of extreme wettability patterns on steel substrate. (a) Water droplets (dyed red) were positioned on the superhydrophobic area after chemical etching in Step I. (b) Water (dyed blue) on extreme wettability pattern in air. (c) Dichloromethane (dyed red) on extreme wettability pattern with water-film protection. SEM images of etched steel surfaces are at different magnifications. (d) superhydrophobic region, (e) boundary of dual etching regions, and (f) superhydrophilic region that was obtained by secondary etching.

\subsection{Fabrication of extreme wetting patterns on a $\mathrm{Zn}$ plate}

Likewise, two step chemical deposition method can also be used to prepare extreme wettability patterns on a $\mathrm{Zn}$ plate. The coated $\mathrm{Zn}$ plate was reacted in the mixed solution of $0.1 \mathrm{~mol} \mathrm{~L}^{-1} \mathrm{H}_{2} \mathrm{SO}_{4}$ and $0.2 \mathrm{~mol} \mathrm{~L}^{-1} \mathrm{CuSO}_{4}$ for 40 s to obtain the microstructures. The contact angle of the water droplets in this region reached $160^{\circ}$ and the rolling angle was $6^{\circ}$. Finally, the region that was previously covered by the mask became superhydrophilic by dropping the mixed solution on it. In this way, we had successfully prepared superhydrophilic-superhydrophobic patterns on $\mathrm{Zn}$ plates through this general method [Figure 8b]. The extreme wettability patterns under water can be prepared as well [Figure 8c]. Similarly, through this dual chemical deposition, various extreme wetting patterns can be also fabricated on $\mathrm{Zn}$ plates (see Supplementary Material

The chemically deposited $\mathrm{Zn}$ surface had a large number of irregular particles, which were copper deposited on the $\mathrm{Zn}$ plate surface [Figure 8d]. The copper surface consisted of dendrites in all directions and many dendrites were curved on the support. Figure 8e shows the boundary of superhydrophobic and superhydrophilic regions. After the second deposition of the area that was previously covered by the mask, as shown in Figure 8f, the microstructure of the superhydrophilic $\mathrm{Zn}$ surface was not obviously changed. This is mainly due to the fact that the intensity of this deposition is easy to control. 
(a)

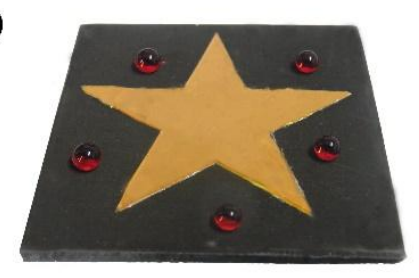

(b)

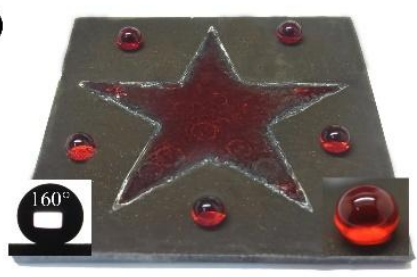

(c)

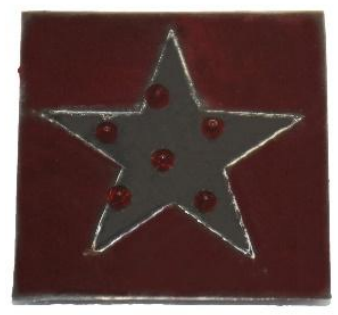

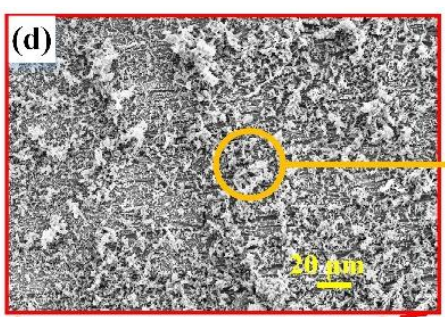

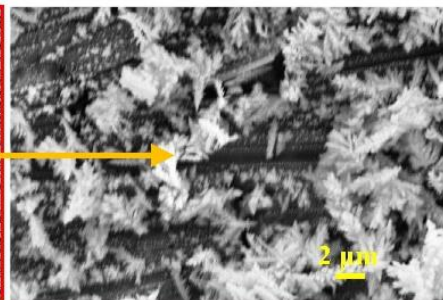

(e)
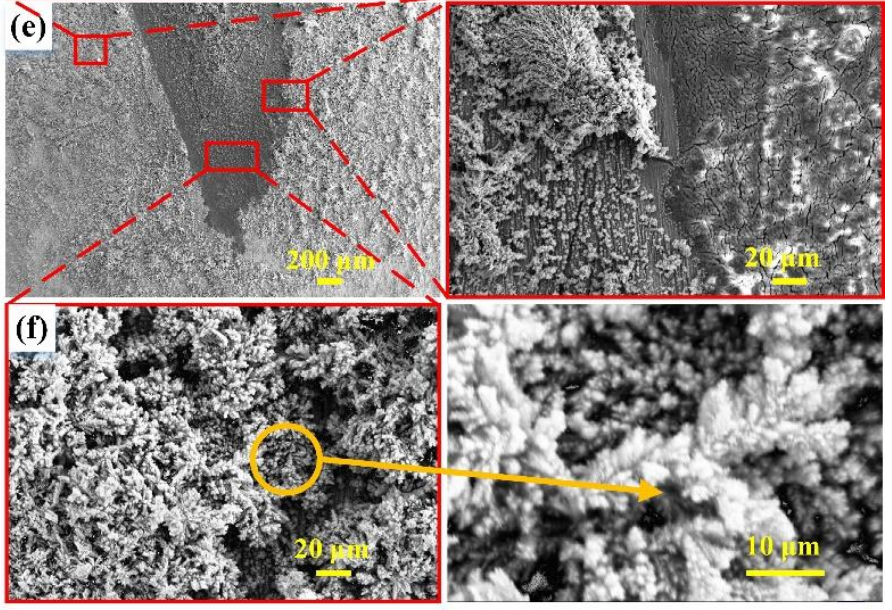

Figure 8. Fabrication of extreme wettability patterns on a Zn substrate. (a) Water droplets (dyed red) were positioned on the superhydrophobic area after chemical deposition in Step I. (b) Water (dyed red) on extreme wettability patterns in air after processing of Step II. (c) Dichloromethane (dyed red) on extreme wettability patterns of Zn surface that was immersed in water. SEM images of deposited Zn surfaces at different magnifications. (d) superhydrophobic region, (e) boundary of dual deposition regions, and (f) superhydrophilic region that was obtained by secondary deposition in Step II.

\subsection{Fabrication of extreme wetting patterns on a Mg alloy plate}

This method can also be applied to fabricate extreme wettability patterns on a $\mathrm{Mg}$ alloy plate. The pretreated $\mathrm{Mg}$ alloy plate was immersed in $0.2 \mathrm{~mol} \mathrm{~L}^{-1} \mathrm{CuSO}_{4}$ solution for $10 \mathrm{~min}$ at $85^{\circ} \mathrm{C}$ to obtain the microstructures. After fluoroalkylsilane modification, superhydrophobic surface on $\mathrm{Mg}$ alloy surface [Figure 9a] was obtained. The surface had a contact angle of $162^{\circ}$ and a rolling angle of about $2^{\circ}$. Finally, extreme wettability patterns on $\mathrm{Mg}$ alloy surface had been prepared after dropping the reaction solution on the hydrophilic region that was covered by the mask previously [Figure 9b]. We can also prepare the extreme wettability patterns containing both superoleophilic and superoleophobic regions under water [Figure 9c]. Similarly, various extreme wetting patterns can also be fabricated on $\mathrm{Mg}$ alloy plates by this dual immersion method (see Supplementary Material Figure S3).

After immersion, a rough green film on the $\mathrm{Mg}$ alloy surface was obtained, which consist of irregular microscale island-like structures [41]. The island-like structures were separated from each other. In the magnified image, many nanosheets with an edge length of about $500 \mathrm{~nm}$ and a thickness of about $70 \mathrm{~nm}$ were present on the surfaces with the sland-like structures and voids [Figure 9d]. After ultrasonic cleaning, the green film completely drops out, leaving gray rough structures. The boundary of the two regions was not very clear [Figure 9e], because the microstructures of the superhydrophilic region [Figure 9f] were similar with those of the superhydrophobic region. 
(a)

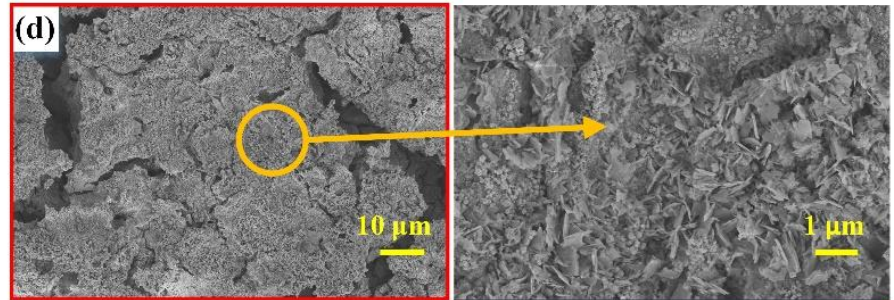

(b)
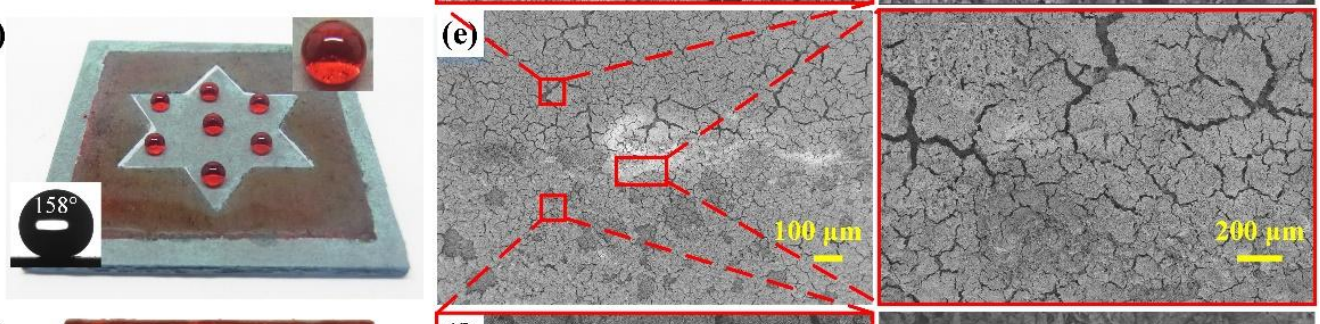

(c)
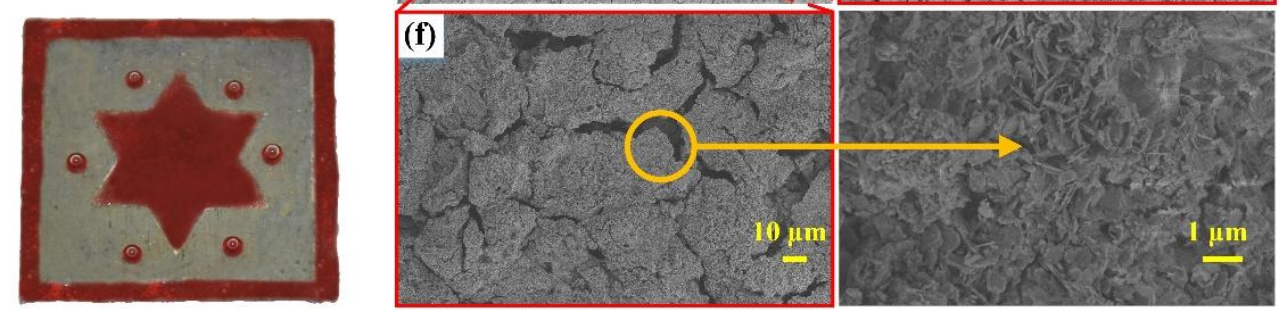

Figure 9. Fabrication of extreme wettability patterns on Mg alloy substrate. (a) Water droplets (dyed red) were positioned on the superhydrophobic area after chemical immersion in Step I. (b) Water (dyed red) on extreme wettability patterns in air after processing of Step II. (c) Dichloromethane (dyed red) on extreme wettability patterns of Mg alloy surface that was immersed in water. SEM images of immersed Mg alloy surfaces at different magnifications. (d) Superhydrophobic region, (e) boundary of dual etching regions, and (f) superhydrophilic region that was obtained by secondary immersion in Step II.

\section{Fog harvest process on the superhydrophilic-superhydrophobic patterns}

$\mathrm{Al}, \mathrm{Mg}$ alloy and $\mathrm{Zn}$ are three widely-used metals in daily life and industrial production. In this section, we selected these three metal substrates with the size of $40 \mathrm{~mm} \times 40 \mathrm{~mm}$ and fabricated the superhydrophilic-superhydrophobic star-shaped patterns with the same size on the three metal surfaces by the method of dual chemical processing. By integrating a surface energy gradient and Laplace pressure gradient [42], surfaces with star-shaped wettability patterns can quickly drive tiny water droplets toward more wettable areas, resulting in higher water collection efficiency than those of uniform superhydrophobic and superhydrophilic surfaces. Comparing the three different metals with the same pattern, it has been shown that there is a large difference in the collection efficiency of the different metals with the same identical star-shaped wettability pattern. Areas of these patterned superhydrophobic domains were made constant.

Figure 10a shows a schematic view of the fog collection system. The fog harvest devices and measurements methods have been described in the methods section. As shown in Figure 10b, under the same collection conditions, the water collection rate (WCR) on the surface of the $\mathrm{Zn}$ plate pattern was the highest compared with the $\mathrm{Al}$ and $\mathrm{Mg}$ alloy plate pattern surfaces. As a result, $1604 \mathrm{mg}$ of water was collected on $\mathrm{Zn}$ surface in one hour. The patterned Zn surface was capable of rapidly draining away condensate with an average of 152 drops on the surface in 30 minutes [Figure 10c]. The patterned Al surface discharged 122 drops during the same mist harvest. However, $\mathrm{Mg}$ alloy plate surface only discharged 47 droplets. Figure $10 \mathrm{~d}$ shows the average mass of a single droplet falling from three metal patterns. It can be seen that the average mass of a single droplet on the Mg alloy surface is much higher than that on the other two metals, indicating that the droplet size is greater from the star-shaped $\mathrm{Mg}$ patterned surface. Larger droplets indicate slower cycles of droplet formation and shedding. This phenomenon may be due to the difference in the extreme wettability of the three metal surfaces and the thermal conductivity of the metal itself, which will be focused on in our future studies. 
$\mathbf{a}$
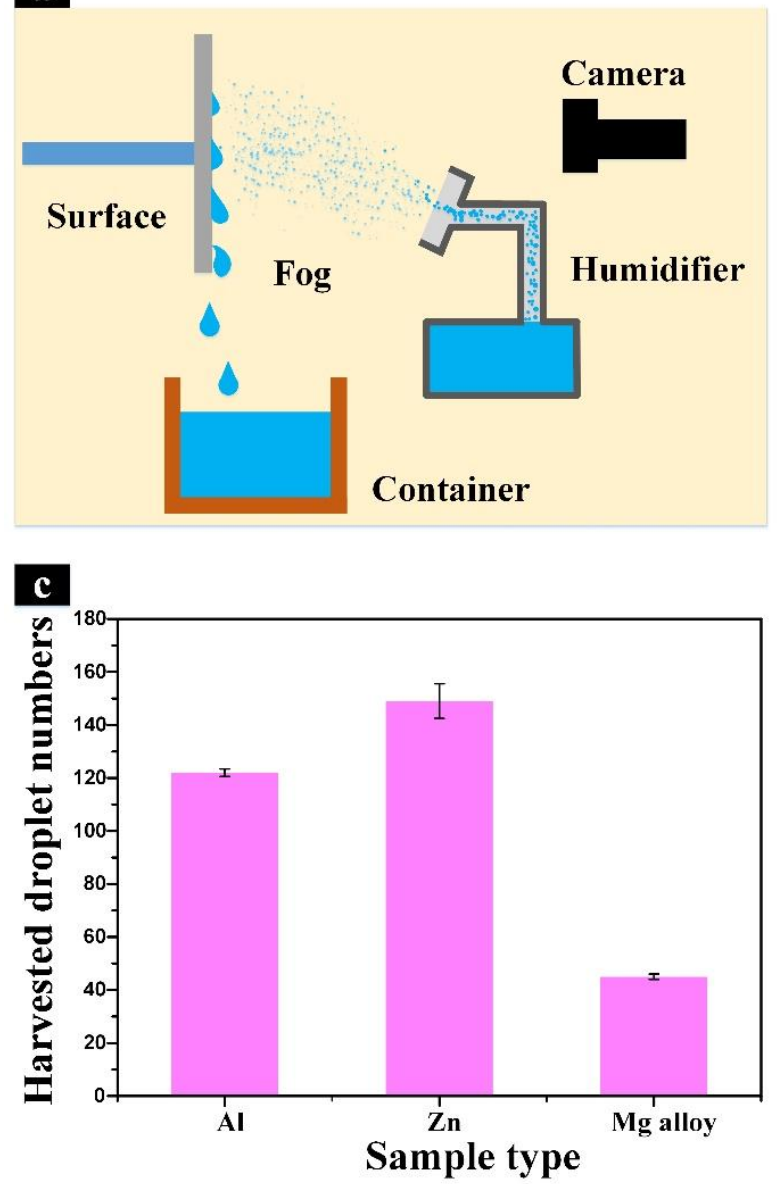

b
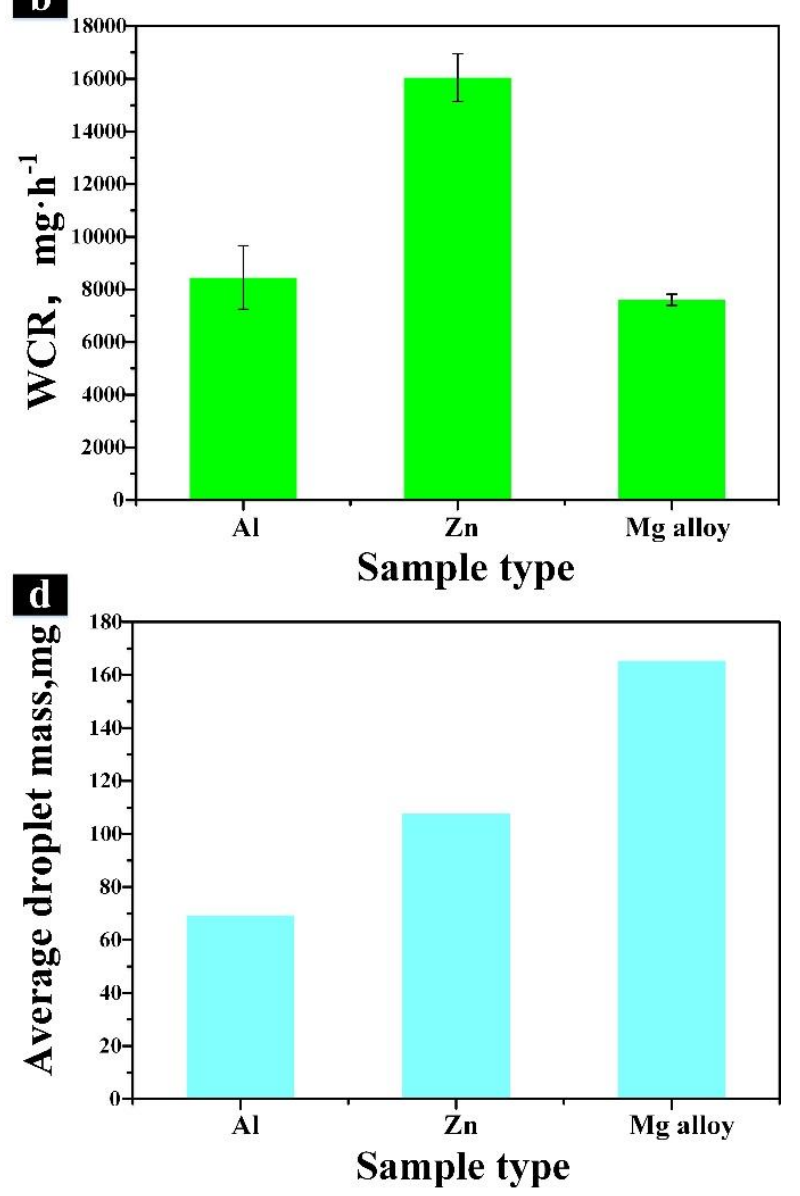

Figure 10. Fog harvest results on different surfaces. (a) Schematic of the fog harvest set. (b) Water collection rate of different surfaces in the fog harvest process. (c) Droplet number of water collected on different surfaces for $30 \mathrm{~min}$ fog harvest process. (d) Average mass of each collected droplet in fog harvest processes on different surfaces.

To better understand the fog-harvesting behavior and result of these substrates, digital camera was used to record the water collection processes on these surfaces. As shown in Figure 11a, a pentagon-pattern (depicted by the red dotted line) was used to observe the water collection process. Droplets were initially captured everywhere on the patterned surface. Due to the surface energy gradient, tiny droplets on the superhydrophobic region were pushed into the superhydrophilic region to form larger droplets (see blue arrows). The tips of the star produced a Laplace pressure gradient from the shape gradient, which further enhanced this directional movement of the water droplet [43-45]. When the size of these droplets increased beyond a certain threshold, the droplets became unstable and rolled off both the superhydrophobic and superhydrophilic surface as a result of gravity (see black arrows). After the droplets were released from the original position, a new collection cycle began immediately. In addition, the self-clearing of the droplets from a superhydrophobic surface allowed new droplets to continuously nucleate and grow, thereby enhancing water collection. As shown in Figure 11, the number of droplets collected in the superhydrophobic region of the Zn plate surface was much larger than the surface of the $\mathrm{Mg}$ plate and larger than that of the $\mathrm{Al}$ plate. In addition, the circulation of droplets on the surface of the $\mathrm{Zn}$ plate (see red circle) grew and then fell off faster than those on the other two metals, resulting in a higher mist collecting efficiency on the patterned surface of the Zn plate. As shown in Figure 11c, the Mg alloy surface collected very little droplets in the superhydrophobic region and a large droplet in the superhydrophilic region, resulting in an average single droplet mass much higher than the other two metals (see pink circle). These phenomena indicate that star-shaped extreme wettability patterns on $\mathrm{Zn}$ plates have better fog collection efficiency compared with the same patterns on $\mathrm{Al}$ and $\mathrm{Mg}$ alloy plate. 

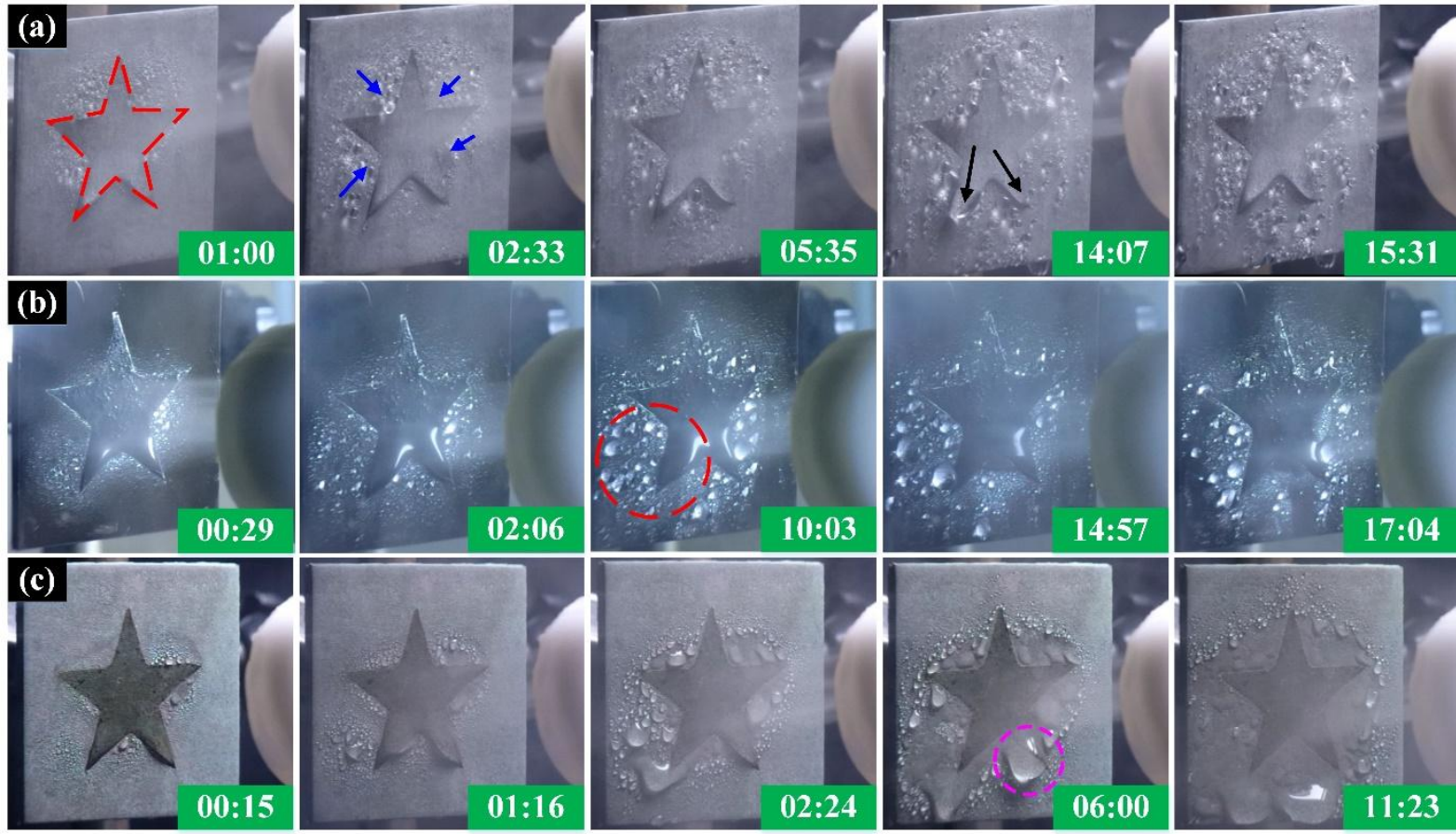

Figure 11. Fog harvest processes on different metal surfaces: (a) Al, (b) Zn, (c) Mg alloy.

\section{Conclusion}

In summary, we developed a dual-chemical-processing approach without a special modification method to selectively fabricate superhydrophilic and superhydrophobic regions on various metal substrates, respectively. Superhydrophilicsuperhydrophobic patterns with different shapes were fabricated on a metal substrate by mask-coating chemical processing and syringe dripping. This method is simple, fast, low-cost and generally applicable to various metal substrates and it involves chemical etching, chemical impregnation, and chemical deposition. Superhydrophobic surfaces with super-hydrophilic five-pointed star patterns were prepared on three metals using an optimized chemical processing method, and they were tested o fog harvest. Our results show that the water collection efficiency on the different metal patterned surfaces is very different. These investigations can provide insights into the design and development of materials with controllable wettability to achieve efficient water or liquid collection techniques.

\section{Acknowledgements}

This project was financially supported by National Natural Science Foundation of China (NSFC, 51605078), the Science Fund for Creative Research Groups of NSFC (51621064), National Basic Research Program of China (2015CB057304), Aviation Science Fund (2017ZE63012), the Doctoral Scientific Research Foundation of Liaoning Province (201601058) and the Fundamental Research Funds for the Central Universities (DUT17JC25). Y. Lu acknowledges the support from EPSRC project EP/N024915/1.

\section{References:}

[1] M. Long, S. Peng, W. Deng, X. Yang, K. Miao, N. Wen, X. Miao, W. Deng, J. Colloid Interf. Sci. 508 (2017) 18-27.

[2] J.A. Maurer, M.J. Miller, S.F. Bartolucci, J. Colloid Interf. Sci. 524 (2018) 204-208.

[3] K. Tu, X. Wang, L. Kong, H. Guan, Materials \& Design. 140 (2018) 30-36.

[4] K. Chen, J. Jia, Y. Zhao, K. Lv, C. Wang, Materials \& Design. 135 (2017) 69-76.

[5] H. Hu, J. Wen, L. Bao, L. Jia, D. Song, B. Song, G. Pan, M. Scaraggi, D. Dini, Q. Xue, Science Advances. 3 (2017) e1603288.

[6] B. Bhushan, C.J. Yong, Prog. Mater. Sci. 56 (2011) 1-108.

[7] I.P. Parkin, R.G. Palgrave, Journal of Materials Chemistry. 15 (2005) 1689.

[8] S. Farhadi, M. Farzaneh, S.A. Kulinich, Appl. Surf. Sci. 257 (2011) 6264-6269.

[9] Y. Wang, J. Xue, Q. Wang, Q. Chen, J. Ding, Acs Appl Mater Interfaces. 5 (2013) 3370-3381.

[10] Y. Liu, Z. Wang, Sci. Rep.-UK. 6 (2016) 33817. 
[11] E. Cho, C. Chang-Jian, H. Chen, K. Chuang, J. Zheng, Y. Hsiao, K. Lee, J. Huang, Chem. Eng. J. 314 (2017) 347-357.

[12] B. Zhang, X. Hu, Q. Zhu, X. Wang, X. Zhao, C. Sun, Y. Li, B. Hou, Chem. Eng. J. 312 (2017) 317-327.

[13] F. Chen, Y. Lu, X. Liu, J. Song, G. He, M.K. Tiwari, C.J. Carmalt, I.P. Parkin, Adv. Funct. Mater. 27 (2017) 1702926.

1 [14] X. Hou, Y. Hu, A. Grinthal, M. Khan, J. Aizenberg, Nature. 519 (2015) 70-73.

2 [15] H. Zhang, Y.Y. Lee, K.J. Leck, N.Y. Kim, J.Y. Ying, Langmuir the Acs Journal of Surfaces \& Colloids. 23 (2007) 4728.

4 [16] Y. Xu, J.T. Watson, M.L. Bruening, Anal. Chem. 75 (2003) 185-190.

5 [17] L.G. Griffith, S. Lopina, Biomaterials. 19 (1998) 979-986.

$718]$ H. Gau, S. Herminghaus, P. Lenz, R. Lipowsky, Science. 283 (1999) 46-49.

8 [19] M.J. Hancock, F. Yanagawa, Y.H. Jang, J. He, N.N. Kachouie, H. Kaji, A. Khademhosseini, Small. 8 (2012) 326.

9 [20] T.M. Schutzius, I.S. Bayer, G.M. Jursich, A. Das, C.M. Megaridis, Nanoscale. 4 (2012) 5378.

21] L. Zhang, J. Wu, M. Hedhili, X. Yang, P. Wang, J. Mater. Chem. A. 3 (2015) 2844-2852.

[22] T. Sun, G. Wang, H. Liu, L. Feng, L. Jiang, D. Zhu, J. Am. Chem. Soc. 125 (2003) 14996-14997.

23] H.S. Lim, J.T. Han, D. Kwak, A. Meihua Jin, K. Cho, J. Am. Chem. Soc. 128 (2006) 14458-14459.

[24] S. Nishimoto, M. Becchaku, Y. Kameshima, Y. Shirosaki, S. Hayakawa, A. Osaka, M. Miyake, Thin Solid Films. 558 (2014) 221-226.

[25] S. Feng, S. Wang, C. Liu, Y. Zheng, Y. Hou, Chem. Commun. 51 (2015) 6010.

[26] Z. Gao, J. Sun, S. Peng, L. Yao, Y. Qiu, Appl. Surf. Sci. 256 (2009) 1496-1501.

[27] J. Wu, H.J. Bai, X.B. Zhang, J.J. Xu, H.Y. Chen, Langmuir. 26 (2010) 1191-1198.

[28] Y. Lai, C. Lin, H. Wang, J. Huang, H. Zhuang, L. Sun, Electrochem. Commun. 10 (2008) 387-391.

[29] H. Kinoshita, A. Ogasahara, Y. Fukuda, N. Ohmae, Carbon. 48 (2010) 4403-4408.

[30] X. Yang, J. Song, J. Liu, X. Liu, Z. Jin, Sci. Rep.-UK. 7 (2017).

31] A.R. Parker, C.R. Lawrence, Nature. 414 (2001) 33-34.

[32] Q. Schiermeier, Nature. 505 (2014) 10-11.

[33] H. Bai, L. Wang, J. Ju, R. Sun, Y. Zheng, L. Jiang, Adv. Mater. 26 (2014) 5025-5030.

[34] H. Zhu, F. Yang, J. Li, Z. Guo, Chem. Commun. 52 (2016).

[35] H.J. Flitt, D.P. Schweinsberg, Corros. Sci. 52 (2010) 1905-1914.

[36] W. Xu, J. Song, J. Sun, Y. Lu, Z. Yu, ACS Appl. Mater. Inter. 3 (2011) 4404.

[37] A.M. Beccaria, L. Chiaruttini, Corros. Sci. 41 (1999) 885-899.

[38] F. Dong, W. Guo, S.W. Chu, C.S. Ha, Chem. Commun. 46 (2010) 7498-7500.

[39] Y. Lu, J. Song, X. Liu, W. Xu, Y. Xing, Z. Wei, ACS Sustain. Chem. Eng. 1 (2013) 102-109.

40] Y. Lu, X. Liu, W. Xu, J. Song, Y. Xing, J. Sun, Appl. Surf. Sci. 263 (2012) 297-301.

[41] J. Song, Y. Lu, S. Huang, X. Liu, L. Wu, W. Xu, Appl. Surf. Sci. 266 (2013) 445-450.

[42] L. Zhang, J. Wu, M. Hedhili, X. Yang, P. Wang, J. Mater. Chem. A. 3 (2015) 2844-2852.

[43] É. Lorenceau, D. Quéré, J. Fluid Mech. 510 (2004) 29-45.

[44] N.A. Malvadkar, M.J. Hancock, K. Sekeroglu, W.J. Dressick, M.C. Demirel, Nat. Mater. 9 (2010) 1023-1028.

[45] J. Zhang, Y. Han, Langmuir. 23 (2007) 6136-6141. 